\title{
O Cebes na luta durante a pandemia da Covid-19
}

Lucia Souto $\mathbf{1}^{\mathbf{2}}$, Carlos Silva1

DOI: $10.1590 / 0103-1104202113100$

NESSES DOIS ÚLTIMOS ANOS, A PANDEMIA DA COVID-19 NO BRASIL tem-se traduzido como evento catastrófico, que, para além de expor a ênfase das políticas públicas do governo federal contra os direitos de cidadania conferidos pela Constituição Federal de 1988, evidencia, cada vez mais, determinação política de destruição do papel civilizatório do Estado na garantia de direitos individuais e coletivos.

Essa é uma atitude política criminosa, que desconsidera a vulnerabilidade e a enorme desigualdade na população brasileira, que só fazem aumentar nessa crise sanitária. Ao contrário do que deveria se dar, moral e constitucionalmente, mister fosse implantar políticas voltadas para controle, superação e de redução dos impactos econômicos, sociais, culturais, educacionais e de ciência e tecnologia acirrados pela pandemia. De forma similar, a necessidade de implementar ações emergenciais de reconhecimento científic o em âmbito mundial e nacional, como: disponibilização de vacinas, isolamento social contra situações de aglomerações, uso de máscaras e de álcool em gel, entre outras medidas que reduzissem a transmissão do vírus. Todas essas práticas associadas a medidas de apoio direto às pessoas, famílias e aos trabalhadores, como política de transporte, com apoio a moradias adequadas, acesso à alimentação, entre outras tantas necessidades básicas que deveriam ser minimizadas por auxílio emergencial robusto e com período mais durável até que a situação pandêmica melhorasse.

Hoje, mais do que isso, que se tenha um plano de enfrentamento também das consequências de uma pandemia descontrolada de forma proposital pelo governo federal. Será preciso planejar política que dê alívio, subsídio ao luto pela perda da vida de mais de 600 mil pessoas cujas mortes desampararam inúmeras crianças e adolescentes - hoje órfãos -, desestruturam famílias cujos idosos (o grupo inicialmente mais vulnerável ao adoecimento e morte pela Covid-19) muitas vezes amparavam suas famílias com a aposentadoria, ainda que de valores mínimos, mas que se responsabilizavam pela renda dessas pessoas todas vulnerabilizadas.

As atividades do Centro Brasileiro de Estudos de Saúde (Cebes) na luta pela democratização da sociedade e a defesa dos direitos sociais, em particular o direito universal à saúde, foram intensificadas por articulação parceiras de pessoas e instituições, movimentos sociais, comprometidos com a reforma sanitária brasileira na expectativa de fortalecimento e mobilização contra essa atual conjuntura de sucateamento e desmonte do Sistema Único de Saúde (SUS) e dos direitos conquistados por meio da Constituição Cidadã!

A funesta agenda de reformas conduzidas neste período de pandemia, pelos neoliberais, segue centrada na austeridade fiscal e na redução do papel do Estado na economia e na defesa
${ }^{1}$ Centro Brasileiro de Estudos de Saúde (Cebes) - Rio de Janeiro (RJ), Brasil. luciafsouto@yahoo.com.br

2 Fundação Oswaldo Cruz (Fiocruz), Escola Nacional de Saúde Pública Sergio Arouca (Ensp) - Rio de Janeiro (RJ), Brasil. 
do bem-estar da população. Reformas trabalhista, previdenciária, tributária e de privatizações do Estado que não permitem crescimento e desenvolvimento da nação e que, paulatinamente, levam o País ao desemprego, ao retorno da fome e da miséria com pioras de indicadores de vida e de saúde, dos indicadores fiscais, contra a política de transparência da utilização dos recursos públicos e de combate à corrupção'.

A situação só se agrava, desde que foi registrado (26/02/2020) o primeiro caso de Covid-19 no Brasil, o primeiro caso de transmissão interna (05/03/2020) e a notificação da primeira morte por Covid-19 no País (17/03/2020). O SUS, como fortaleza nacional da saúde, por sua descentralização, regionalização e universalidade com capilaridade e cobertura territorial com rede de Atenção Primária à Saúde, contribuiu marcadamente para o enfrentamento da pandemia. Inicialmente, com abertura de leitos hospitalares e maior oferta de cuidados intensivistas, organizando a assistência clínica, para casos graves, na expectativa de redução do número de mortes, seguida da estratégia de dar suporte à saúde da população com atendimento, diagnóstico e acompanhamento dos casos leves a partir dos territórios locais ${ }^{2}$.

Entretanto, no plano de destruição do País e de seus quadros de ciência, de educação, de saúde, de inovação e tecnologia, de pesquisas, da cultura etc., o SUS tem sofrido inúmeros ataques quer com cortes no financiamento, prioridade de recursos para a saúde privada e, por exemplo, com a recente proposta de privatização da Estratégia Saúde da Família (ESF). Isso cria o imperativo ético de as entidades de saúde coletiva, comprometidas com a reforma sanitária brasileira, juntarem-se entre si e em parceria com as de outros setores para enfrentar a reconstrução do Brasil.

A força de um espaço plural suprapartidário - reunindo ativistas, lideranças, pesquisadores, professores, profissionais e estudantes com a perspectiva de se articular e participar de frentes e alianças com diversos movimentos sociais, grupos e entidades da sociedade - pressupõe mais robustez de luta pela democratização da sociedade, pela defesa dos direitos sociais e pela soberania do País. Diante desse sofrimento e de tantos ataques contra a ciência, criam-se resiliência e resistência com mobilização e debates reflexivos que sedimentam a produção de conhecimento por análise crítica das políticas de saúde compartilhada pelos sujeitos que constroem e lutam pela história desta nação. São traçadas, deste modo, estratégias de algumas frentes de ação pela vitória de recondução a justiça, equidade, democracia e soberania de um Brasil de direitos constitucionais.

Referimo-nos, pois, a Frente pela Vida, Frente Brasil Popular, Povo sem Medo, Manifesto Intersetorial Saúde, Educação e Assistência Social, que congregaram inúmeras entidades fortalecidas pelo Conselho Nacional de Saúde (CNS), Conselho Nacional de Secretários de Saúde (Conass), Conselho Nacional de Secretarias Municipais de Saúde (Conasems), entre outros.

A mobilização tem sido enorme, e uma das primeiras respostas foi a de criação de um Plano Nacional de Enfrentamento à Pandemia de Covid-193 criado por instituições ligadas à Frente pela Vida, que o elaboraram diante da omissão, irresponsabilidade e inépcia das autoridades federais ante a pandemia e pela necessidade de a sociedade brasileira superar a crise sanitária e suas consequências.

Foram realizadas 'Marchas pela Vida'. 'Manifestações Públicas nas Ruas contra o Governo Federal' por sua postura genocida, em inúmeras cidades brasileiras, denominadas, respectivamente, por $25 \mathrm{M}, 19 \mathrm{~J}, 29 \mathrm{~J}, 7 \mathrm{~S}, 02 \mathrm{O}$ e outras. Cerimônias de denúncias contra o aumento exponencial de número de mortos pela Covid-19, com entrega de documento ao Legislativo, ao Executivo e ao Judiciário. Reinvindicações de renovação e de desenvolvimento à plena potência do SUS. Argumentos e solicitações contra as iniquidades acentuadas pela pandemia, geradas por raça/cor, classe, etnia, gênero, idade, deficiências, origem geográfica e orientação 
sexual. Outrossim, que fossem considerados diferentes segmentos populacionais na produção de dados e estratégias de ação de enfrentamento da pandemia, em especial, a vulnerabilidade dos povos indígenas e outros grupos isolados ou de recente contato, que demandam medidas urgentes e prioritárias ${ }^{4}$.

Outra medida resultante da mobilização das entidades foi a instituição de Comissão Parlamentar de Inquérito sobre a Pandemia de Covid-19 (CPI da Pandemia), em que a sociedade exige que sejam apuradas atitudes passíveis de ação criminosa por parte de autoridades federais e, em particular, pelo presidente da república, cujo descaso e abandono da população e do direito à vida, a rejeição e a demora na aquisição de vacinas foram suas tônicas, que agravaram a pandemia. As políticas implementadas por eles foram pautadas na busca pela imunidade de rebanho e na ausência de vacinas, que só facilitaram a circulação do vírus, somadas a atitudes contra todas as medidas de prevenção e segurança da população contra a Covid-19, criando falsas notícias, propalando medicamentos não reconhecidos pela ciência para tratamento de pacientes, deixando faltar medicação e equipamentos, sim, básicos para a defesa da vida, como foi o caso da falta de oxigênio, de sedativos e de material de intubação, como ocorreu no estado de Manaus 5 .

Hoje, diante da maior calamidade de nossa história, o governo brasileiro se destaca pelo negacionismo, que levou o Brasil ao maior número de mortes por Covid-19 (607.125 em $29 / 11 / 2021)^{6}$ e à pior gestão da pandemia do mundo, tornando-o uma ameaça global. Nesse contexto, o Cebes vem desempenhando um papel de liderança na defesa da vida e saúde da população brasileira, segue articulado em diversas frentes de luta, fortalecendo a colaboração intersetorial com várias políticas sociais ${ }^{7}$ e estimulando a mobilização da sociedade para a reconstrução do País. É um momento que exige o fortalecimento de nossa união para superarmos essa catástrofe e afirmarmos um projeto de país solidário e soberano, que enfrente a nossa desigualdade explosiva, marca de uma nação escravocrata.

\section{Colaboradores}

Souto L (0000-0003-2270-8424)* e Silva C (0000-0002-7550-7610 )* contribuíram igualmente para a elaboração do manuscrito.
${ }^{\star}$ Orcid (Open Researcher and Contributor ID). 


\section{Referências}

1. Costa AM, Rizzotto MLF, Lobato LVC. Fome, desemprego, corrupção e mortes evitáveis: faces da necropolítica. Saúde debate. 2021; 45(130):555-562.

2. Giovanella L, Martufi V, Ruiz DC, et al. A contribuição da Atenção Primária à Saúde na rede SUS de enfrentamento à Covid-19. Saúde debate. 2021; 45(130):748-762.

3. Frente pela Vida. Plano Nacional de Enfrentamento à Pandemia da Covid-19. [acesso em 2021 out 29]. Disponível em: https://frentepelavida.org.br/uploads/documentos/PEP-COVID-19_v3_01_12_20. pdf).

4. Frente pela Vida. Manifesto Dia Nacional da Saúde: em defesa da vida, do SUS e da democracia! [acesso em 2021 out 29]. Disponível em https://frentepelavida.org.br/.

5. Brasil. Senado Federal. Comissão Parlamentar de Inquérito da Pandemia. Relatório Final. [acesso em
2021 out 29]. Disponível em: http://estaticogl.globo. com/2021/10/26/relatorio_final_26102021_12h40. $\mathrm{pdf}$ ? ga $=2.30212924 .264867225 .1635518092-$ 723161694.1619708332 .

6. Brasil. Consórcio de veículos de imprensa com dados das Secretarias de Saúde com acesso em 29/10/2021que registram 607.125 óbitos e 21.780.474 casos de Corona vírus. G1. 2021 out 10. [acesso em 2021 out 29]. Disponível em: https://gl.globo.com/ saude/coronavirus/noticia/2021/10/28/com-media-movel-de-337-mortes-diarias-por-covid-brasil-chega-a-607-mil-vitimas-da-doenca.ghtml.

7. Frente pela Vida. Manifesto Saúde, Educação e Assistência Social em defesa da vida e da democracia. [acesso em 2021 out 29]. Disponível em: http:// cebes.org.br/2021/03/entidades-da-saude-educacao-e-da-assistencia-social-orientam-sobre-o-ensino-presencial-na-pandemia/. 